\title{
ANALISIS POTENSI PAJAK DAERAH DAN RETRIBUSI DAERAH SEBAGAI SUMBER PENDAPATAN ASLI DAERAH KABUPATEN HALMAHERA UTARA
}

\author{
Meilin Hehega ${ }^{1}$, Herman Karamoy ${ }^{2}$, Natalia Y.T Gerungai ${ }^{3}$ \\ 12 Jurusan Akuntansi, Fakultas Ekonomi dan Bisnis Universitas Sam Ratulangi, Jl. Kampus Bahu, Manado, \\ 95115, Indonesia
}

Email : meilinhehega@gmail.com

\begin{abstract}
This study aims to analyze the types of local taxes and user charges on the growth and contribution to total taxes and levies. Identify into prime, potential, growing and underdeveloped classifications. The data used are primary and secondary data in North Halmahera Regency with research period of 2012 - 2016. Analyzer used is growth analysis, contribution analysis and overlay analysis. The results of this study indicate that the growth and contribution of types of taxes and levies fluctuated during the 5-year budget. Based on the analysis of restaurant tax overlay and levy building permit is a type of local tax that has the potential to be developed in order to increase local revenue.
\end{abstract}

Keywords: growth, contribution, potential of local taxes and levies

\section{PENDAHULUAN}

Salah satu penerimaan Pendapatan Asli Daerah (PAD) berasal dari pajak daerah. Pajak dan retribusi daerah adalah salah satu pendapatan asli daerah yang diterima dengan rutin. Besar penerimaan dari pajak dan retribusi daerah berbeda-beda untuk setiap daerah, tergantung potensi dan cara pengelolaan yang dilakukan oleh masing-masing daerah. Pemerintah daerah Kabupaten Halmahera Utara telah berupaya untuk meningkatkan Pendapatan Asli Daerah (PAD) dengan berbagai cara salah satunya memperluas cakupan pungutan pajak dan retribusi daerah. Tabel 1 menunjukkan perkembangan pajak daerah dan retribusi daerah Kabupaten Halmahera Utara tahun 2012-2016.

Tabel 1. Perkembangan Realisasi PAD Kabupaten Halmahera Utara Tahun 2012-2016

\begin{tabular}{rcrrrrr}
\hline No & $\begin{array}{c}\text { Tahun } \\
\text { Anggaran }\end{array}$ & $\begin{array}{c}\text { Pajak } \\
\text { Daerah }\end{array}$ & $\begin{array}{c}\text { Retribusi } \\
\text { Daerah }\end{array}$ & $\begin{array}{c}\text { Hasil } \\
\text { pengolahan } \\
\text { kekayaan } \\
\text { daerah yang } \\
\text { dipisahkan }\end{array}$ & $\begin{array}{c}\text { Lain-lain } \\
\text { pendapatan } \\
\text { daerah } \\
\text { yang sah }\end{array}$ & $\begin{array}{c}\text { Total } \\
\text { PAD }\end{array}$ \\
\hline 1 & 2012 & $4.194 .511 .942,00$ & $7.820 .577 .653,78$ & $305.384 .950,00$ & $100.801 .425 .071,79$ & $113.121 .899 .617,57$ \\
2 & 2013 & $11.260 .109 .198,00$ & $15.821 .885 .029,00$ & $465.779 .835,00$ & $75.782 .685 .697,25$ & $103.330 .459 .759,25$ \\
3 & 2014 & $9.496 .370 .861,00$ & $25.869 .023 .293,00$ & $881.392 .446,00$ & $79.567 .469 .141,77$ & $115.814 .255 .741,77$ \\
4 & 2015 & $11.182 .603 .939,00$ & $32.340 .310 .564,00$ & $76.000 .000,00$ & $92.857 .335 .159,06$ & $136.456 .249 .662,06$ \\
5 & 2016 & $12.684 .435 .826,00$ & $28.907 .695 .889,00$ & $1.608 .014 .985,00$ & $37.569 .380 .596,55$ & $80.769 .527 .296,55$ \\
\hline
\end{tabular}

Dapat dilihat selama lima tahun realisasi penerimaan dari seluruh sumber-sumber Pendapatan Asli Daerah (PAD) di Kabupaten Halmahera Utara mengalami fluktuasi. PAD dari setiap jenis pajak dan retribusi perlu untuk diukur agar potensi yang ada dapat dikelola dan dikumpulkan secara maksimal. Dalam penentuan target penerimaan pajak dan retribusi daerah lebih didasarkan pada perkiraan. Perkiraan dari target sebenarnya tidak dapat melihat potensi sebenarnya yang ada pada masyarakat, potensi penerimaan daerah untuk masingmasing jenis pajak dan retribusi daerah belum dihitung secara menyeluruh. Setiap tahun antara realisasi dan target selalu terjadi selisih perkiraan yang berbeda dimana seringkali realisasi melampaui target dan juga sebaliknya, disebabkan oleh ketikmampuan daerah dalam membuat strategi dan memetakan potensi pajak daerah dan retribusi daerah. Hal ini 
menunjukan bahwa pajak dan retribusi daerah Kabupaten Halmahera Utara sebenarnya belum dikelola dengan baik potensi yang ada.

\section{TINJAUAN PUSTAKA}

Pengertian Akuntansi. Pontoh (2013:1) akuntansi merupakan sistem informasi untuk mengukur kegiatan bisnis, pemrosesan data dan menyampaikan hasilnya kepada para pengambil keputusan.

Pengertian Akuntansi Pajak. Pohan (2013:10) akuntansi pajak merupakan penyediaan informasi perpajakan, bisnis, transaksi keuangan dan aspek perpajakan suatu entitas.

Pengertian Pajak. Sari (2013:34) pajak merupakan iuran dari masyarakat kepada Negara yang terutang dan dapat dipaksakan berdasarkan undang-undang yang berlaku secara umum.

Pengertian Pajak Daerah. Mardiasmo (2016:68) pajak daerah memiliki arti hampir sama, yaitu pajak dipungut oleh daerah berdasarkan peraturan yang telah ditetapkan oleh daerah untuk kepentingan dan kebutuhan pemerintah daerah.

Pengertian Retribusi Daerah. Mardismo (2011:15) retribusi merupakan pungutan atas pembayaran jasa dan pemberian izin tertentu yang disediakan oleh pemerintah untuk kepentingan orang pribadi atau badan.

Pengertian Potensi. Rizaldy (2015) potensi merupakan sesuatu yang sudah ada, hanya saja belum di dapat atau diperoleh ditangan. Mengidentifikasi faktor-faktor yang mempengaruhi pendapatan merupakan bagian dari salah satu upaya menggali potensi.

Pengertian Pendapatan Asli Daerah. Waney (2015) adalah sumber pedapatan yang dapat dengan bebas digunakan masing-masing daerah untuk menyelenggarakan pembangunan daerah.

Pertumbuhan. Halim (2004:163) Pertumbuhan dilakukan agar dapat mengetahui tingkat pertumbuhan dari masing-masing pajak dan retribusi daerah.

Kontribusi. Frediyanto (2010) Kontribusi adalah suatu penerimaan pajak terhadap Pendapatan Asli Daerah yang dapat disumbangkan.

\section{METODE PENELITIAN}

Jenis Penelitian. Husnia (2016:4) Penelitian deskriptif yang memberikan penggambaran secara sistematis mengenai fakta, sifat, hubungan serta peristiwa yang di selidiki.

Tempat Waktu Penelitian. yaitu di Dinas Pendapatan, Pengelolaan, keuangan dan Aset Daerah kabupaten Halmahera Utara. Dimulai bulan Juni 2017 sampai selesai.

Prosedur Penelitian. Dengan melihat permasalahan yang ada di Dinas Pendapatan, Pengelolaan, Keuangan dan Aset Daerah supaya dapat diteliti lebih lanjut, dan mengumpulkan data yang diperlukan untuk menganalisis untuk mendapatkan kesimpulan.

Jenis Data. Sutarman (2012:3) data kualitatif adalah data yang dihasilkan dari wawancara, analisis dokumen, dan observasi. Dalam penelitian ini penulis menggunakan data kualitatif yang dihasilakn dari wawancara dan bahan tertulis.

Metode Analisis Data. Analisis yang digunakan yaitu analisis tingkat pertumbuhan, analisis tingkat kontribusi dan analisis overlay untuk mengetahui potensi pajak daerah di Kabupaten Halmahera Utara.

Analisis Tingkat Pertumbuhan. Rumus menghitung tingkat pertumbuhan pajak dan retribusi daerah adalah sebagai berikut:

Pertumbuhan $=\frac{\text { jumlah jenis pajak tahun tertentu-jumlah jenis pajak tahun sebelumnya }}{\text { Jumlah jenis pajak tahun sebelumnya }} \times 100 \%$ 
Analisis Tingkat Kontribusi. Rumus menghitung tingkat kontribusi pajak dan retribusi daerah adalah sebagai berikut:

$$
\text { Kontribusi }=\frac{\text { Realisasi penerimaan jenis pajak }}{\text { Realisasi penerimaan rata-rata pajak }} \times 100 \%
$$

\section{Analisis Overlay}

Tabel 2. Matriks Komposisi

\begin{tabular}{ccc}
\hline Kontribusi & $\mathrm{zXi} \geq 1$ (tinggi) & $\mathrm{zXi}<1$ (rendah) \\
Pertumbuhan & Prima & Berkembang \\
$\mathrm{zXi} \geq 1$ (tinggi) & Potensial & Terbelakang \\
\hline $\mathrm{tXi}<1$ (rendah) &
\end{tabular}

\section{HASIL PENELITIAN DAN PEMBAHASAN}

\subsection{Hasil Penelitian}

Pemerintah Kabupaten Halmahera Utara sampai dengan saat ini mengelola sembilan jenis pajak yaitu: pajak hotel, pajak restoran, pajak hiburan, pajak reklame, pajak penerangan jalan, pajak mineral bukan logam, BPHTB, PBB, dan pajak air bawa tanah. Dan dua puluh tige jenis retribusi daerah yaitu: Ret. Pelayanan persampahan, Ret. IMB, Ret. Pelayanan kesehatan, Ret. Cetak KTP dan AKTE, Ret. Pengujian kendaraan bermotor, Ret. Terminal, Ret. Izin trayek, Ret. Parker, Ret. Jasa pelabuhan laut, Ret. Jasa pelabuhan udara, Ret. Menara Telkom, Ret. Rumah potong hewan, Ret. Izin gangguan, Ret. Perizinan tertentu, Ret. Pelayanan pasar, Ret. Tempat rekreasi dan olaraga, Ret. Cetak peta, Lain-lain pendapatan daerah yang dipisahkan, Sumbangan pihak ketiga, Jasa umum ketenagakerjaan, Ret. Izin tempat penjualan minuman, PKB mobil penumpang sedan, PKB mobil penumpang minibus.

\subsection{Pembahasan}

Pertumbuhan Jenis Pajak dan Retribusi Daerah. Berbagai jenis pajak dan jenis retribusi diatas dapat diukur dengan tingkat pertumbuhan, hal ini dapat dilihat pada Tabel 3 dan Tabel 4 berikut ini:

Tabel 3. Rata-rata pertumbuhan pajak berdasarkan jenis pajak daerah Kabupaten Halmahera Utara, tahun 2012-2016 (dalam \%)

\begin{tabular}{llrrrrrr}
\hline \multirow{2}{*}{ No } & \multirow{2}{*}{ Jenis Pajak Daerah } & \multicolumn{9}{c}{ Tahun Anggaran } & \multirow{2}{*}{ Rata-rata } \\
\cline { 2 - 7 } & 2012 & $\mathbf{2 0 1 3}$ & $\mathbf{2 0 1 4}$ & $\mathbf{2 0 1 5}$ & $\mathbf{2 0 1 6}$ & \\
\hline 1 & Pajak Hotel & 0 & 0,28 & 0,05 & 0,06 & $-0,04$ & 0,07 \\
2 & Pajak Restoran & 0 & 11,54 & $-0,57$ & 0,24 & 0,26 & 2,29 \\
3 & Pajak Hiburan & 0 & $-0,38$ & 1,31 & $-0,17$ & $-0,05$ & 0,14 \\
4 & Pajak Reklame & 0 & 0 & $-0,51$ & 0,41 & 0,36 & 0,05 \\
5 & Pajak Penerangan jalan & 0 & 0,04 & 0,34 & 0,27 & 0,15 & 0,16 \\
6 & Pajak Mineral bukan & 0 & 0,39 & 0,30 & $-0,29$ & 0,01 & 0,08 \\
7 & Logam & 0 & 0,09 & 0,43 & 1,03 & 0,05 & 0,32 \\
8 & BPHTB & 0 & 0 & 0 & 0,30 & $-0,09$ & 0,04 \\
9 & Pajak Bumi dan Bangunan Bir Bawah Tanah & 0 & 0 & 0 & 0 & 0 & 0 \\
& & 0 & & & & Jumlah Rata-Rata & 3,15 \\
\hline
\end{tabular}


Tabel 4. Rata-rata pertumbuhan retribusi berdasarkan jenis retribusi daerah Kabupaten Halmahera Utara, Tahun 2012-2016 (dalam \%)

\begin{tabular}{|c|c|c|c|c|c|c|c|}
\hline \multirow[t]{2}{*}{ No } & \multirow{2}{*}{$\begin{array}{c}\text { Retribusi } \\
\text { Daerah }\end{array}$} & \multicolumn{5}{|c|}{ Tahun Anggaran } & \multirow[b]{2}{*}{ Rata-rata } \\
\hline & & 2012 & 2013 & 2014 & 2015 & 2016 & \\
\hline 1 & Ret. Pelayanan Persampahan & 0 & $-0,10$ & 0,61 & 0,16 & $-0,15$ & 0,10 \\
\hline 2 & Ret. IMB & 0 & 0,77 & 0,93 & 9,62 & $-0,05$ & 2,25 \\
\hline 3 & Ret. Pelayanan Kesehatan & 0 & 0,90 & 1,40 & $-0,08$ & 0,11 & 0,46 \\
\hline 4 & Ret. Cetak KTP dan AKTE & 0 & $-0,56$ & 0,35 & $-0,11$ & $-0,34$ & $-0,13$ \\
\hline 5 & Ret. Pengujian Kendaraan Bermotor & 0 & 0,10 & $-0,02$ & $-0,69$ & 0 & $-0,12$ \\
\hline 6 & Ret. Terminal & 0 & 0,03 & 0,10 & 0 & 0 & 0,02 \\
\hline 7 & Ret. Izin Trayek & 0 & 0,02 & $-0,37$ & $-0,08$ & $-0,06$ & $-0,09$ \\
\hline 8 & Ret. Parkir & 0 & 0,34 & 0,10 & $-0,16$ & $-0,85$ & $-0,11$ \\
\hline 9 & Ret. Jasa Pelabuhan Laut & 0 & 0,07 & 0,26 & $-0,19$ & 0,30 & 0,08 \\
\hline 10 & Ret. Jasa Pelabuhan Udara & 0 & 0,04 & 0,89 & 0,34 & 0,40 & 0,33 \\
\hline 11 & Ret. Menara Telkom & 0 & 0 & 0 & 0,57 & 0 & 0,11 \\
\hline 12 & Ret. Rumah Potong Hewan & 0 & $-0,09$ & $-0,33$ & $-0,17$ & $-0,03$ & $-0,12$ \\
\hline 13 & Ret. Izin gangguan & 0 & 0,69 & $-0,49$ & 0,62 & 0,45 & 0,25 \\
\hline 14 & Ret. Perizinan tertentu & 0 & 0,16 & 0,28 & $-0,30$ & $-0,10$ & 0 \\
\hline 15 & Ret. Pelayanan Pasar & 0 & 0,29 & $-0,29$ & $-0,46$ & 1,14 & 0,13 \\
\hline 16 & Ret. Tempat rekreasi dan olaraga & 0 & 0,26 & 1,36 & $-0,13$ & $-0,43$ & 0,21 \\
\hline 17 & Ret. Cetak Peta & 0 & 0 & 0 & 0 & 0 & 0 \\
\hline 18 & Lain-lain pendaapatan daerah yang dipisahkan & 0 & 4,69 & $-0,94$ & $-0,80$ & 0 & 0,59 \\
\hline 19 & Sumbangan Pihak ketiga & 0 & 0,16 & 0,06 & 0,12 & $-0,13$ & 0,04 \\
\hline 20 & Jasa umum ketenagakerjaan & 0 & 0,29 & 1,15 & 0 & 0 & 0,28 \\
\hline 21 & Ret. Izin tempat penjualan minuman & 0 & 0,39 & 0,28 & 0,08 & $-0,08$ & 0,16 \\
\hline 22 & PKB Mobil Penumpang Sedan & 0 & 0 & 0 & 0 & 0 & 0 \\
\hline \multirow[t]{2}{*}{23} & PKB Mobil Penumpang Minibus & 0 & 0 & 0 & 0 & 0 & 0 \\
\hline & \multicolumn{6}{|c|}{ Jumlah Rata-Rata } & 4,44 \\
\hline
\end{tabular}

Tabel 3 menunjukan bahwa setiap jenis pajak daerah Kabupaten Halut mengalami pertumbuhan yang variatif. Pertumbuhan dari setiap pajak daerah selama lima tahun pengamatan periode tahun 2012 sampai dengan 2016 dengan nilai rata-rati dari yang terbesar sampai yang terkecil adalah; pajak restoran $(2,29 \%)$, BPHTB $(0,32 \%)$, pajak penerangan jalan $(0,16 \%)$, pajak hiburan $(0,14 \%)$, pajak mineral bukan logam $(0,08 \%)$, pajak hotel $(0,07 \%)$, pajak reklame $(0,05 \%)$, PBB $(0,04 \%)$, untuk pajak air bawah tanah belum teridentifikasikan karena baru berjalan 1 tahun anggaran sehingga pertumbuhan nya tidak dapat dihitung. Table 4 menunjukan bahwa pertumbuhan setiap jenis retribusi dari lima tahun pengamatan periode tahun 2012 sampai dengan 2016 dengan nilai rata-rata mulai dari yang terbesar sampai dengan yang terkecil adalah: Ret. IMB (2,25\%), Lain-lain pendaapatan daerah yang dipisahkan $(0,59 \%)$, Ret. Pelayanan Kesehatan $(0,46 \%)$, Ret. Jasa Pelabuhan Udara $(0,33 \%)$, Jasa umum ketenagakerjaan $(0,28 \%)$, Ret. Izin gangguan $(0,25 \%)$, Ret. Tempat rekreasi dan olaraga $(0,21 \%)$, Ret. Izin tempat penjualan minuman $(0,16 \%)$, Ret. Pelayanan Pasar $(0,13 \%)$, Ret. Menara Telkom $(0,11 \%)$, Ret. Pelayanan Persampahan $(0,10$ $\%)$, Ret. Jasa Pelabuhan Laut $(0,08 \%)$, Sumbangan Pihak ketiga $(0,04 \%)$, Ret. Terminal $(0,02 \%)$, Ret. Perizinan tertentu (0,00\%), Ret. Izin Trayek (-0,09\%), Ret. Parkir $(-0,11 \%)$, Ret. Pengujian Kendaraan Bermotor (-0,12 \%), Ret. Rumah Potong Hewan (-0,12\%), Ret. Cetak KTP dan AKTE (-0,13 \%), untuk Ret. Cetak Peta, PKB Mobil Penumpang Sedan, dan PKB Mobil Penumpang Minibus belum dapat diidentifikasi karena masing-masing retribusi tersebut baru berjalan 1 tahun anggaran sehingga pertumbuhannya tidak dapat dihitung.

Kontribusi Jenis Pajak dan Retribusi Daerah. Kontribusi setiap jenis pajak daerah dan retribusi daerah akan membawa pengaruh terhadap total pendapatan pajak daerah, yang akhirnya akan membawa pengaruh kepada total pendapatan asli daerah. Berdasarkan hal tersebut dapat dilihat pada Tabel 5 dan Tabel 6 Berikut ini: 
Tabel 5. Rata-rata kontribusi pajak berdasarkan jenis pajak daerah Kabupaten Halmahera Utara, Tahun 2012-2016 (dalam \%)

\begin{tabular}{llrrrrrr}
\hline \multirow{2}{*}{ No } & \multirow{2}{*}{ Jenis Pajak Daerah } & \multicolumn{9}{c}{ Tahun Anggaran } & \multirow{2}{*}{ Rata-rata } \\
\cline { 3 - 7 } & & $\mathbf{2 0 1 2}$ & $\mathbf{2 0 1 3}$ & $\mathbf{2 0 1 4}$ & $\mathbf{2 0 1 5}$ & $\mathbf{2 0 1 6}$ & \\
\hline 1 & Pajak Hotel & 0,04 & 0,01 & 0,02 & 0,02 & 0,01 & 0,02 \\
2 & Pajak Restoran & 0,13 & 0,62 & 0,31 & 0,33 & 0,37 & 0,35 \\
3 & Pajak Hiburan & 0,01 & 0 & 0 & 0 & 0 & 0 \\
4 & Pajak Reklame & 0,08 & 0,03 & 0,01 & 0,02 & 0,02 & 0,03 \\
5 & Pajak Penerangan jalan & 0,39 & 0,15 & 0,24 & 0,26 & 0,26 & 0,26 \\
6 & Pajak Mineral bukan Logam & 0,26 & 0,13 & 0,21 & 0,12 & 0,11 & 0,16 \\
7 & BPHTB & 0,06 & 0,02 & 0,04 & 0,08 & 0,07 & 0,05 \\
8 & Pajak Bumi dan Bangunan & 0 & 0 & 0,12 & 0,13 & 0,10 & 0,07 \\
9 & Pajak Air Bawah Tanah & 0 & 0 & 0 & 0 & 0 & 0 \\
& & & \multicolumn{7}{c}{ Jumlah Rata-Rata } & 0,94 \\
\hline
\end{tabular}

Tabel 6. Rata-rata kontribusi retribusi berdasarkan jenis retribusi daerah Kabupaten Halmahera Utara, Tahun 2012-2016 (dalam \%)

\begin{tabular}{llrrrrrr}
\hline \multirow{2}{*}{ No Retribusi Daerah } & \multicolumn{9}{c}{ Tahun Anggaran } & Rata- \\
\cline { 2 - 6 } & & $\mathbf{2 0 1 2}$ & $\mathbf{2 0 1 3}$ & $\mathbf{2 0 1 4}$ & $\mathbf{2 0 1 5}$ & $\mathbf{2 0 1 6}$ & \multicolumn{1}{c}{ rata } \\
\hline 1 & Ret. Pelayanan Persampahan & 0,02 & 0 & 0 & 0 & 0 & 0 \\
2 & Ret. IMB & 0,03 & 0,03 & 0,03 & 0,30 & 0,14 & 0,10 \\
3 & Ret. Pelayanan Kesehatan & 0,62 & 0,59 & 0,87 & 0,63 & 0,29 & 0,60 \\
4 & Ret. Cetak KTP dan AKTE & 0,07 & 0,01 & 0,01 & 0 & 0 & 0,01 \\
5 & Ret. Pengujian Kendaraan Bermotor & 0,03 & 0,02 & 0,01 & 0 & 0 & 0,01 \\
6 & Ret. Terminal & 0,01 & 0 & 0 & 0 & 0 & 0 \\
7 & Ret. Izin Trayek & 0 & 0 & 0 & 0 & 0 & 0 \\
8 & Ret. Parkir & 0,01 & 0 & 0 & 0 & 0 & 0 \\
9 & Ret. Jasa Pelabuhan Laut & 0,01 & 0 & 0 & 0 & 0 & 0 \\
10 & Ret. Jasa Pelabuhan Udara & 0 & 0 & 0 & 0 & 0 & 0 \\
11 & Ret. Menara Telkom & 0 & 0 & 0 & 0 & 0 & 0 \\
12 & Ret. Rumah Potong Hewan & 0 & 0 & 0 & 0 & 0 & 0 \\
13 & Ret. Izin gangguan & 0,01 & 0,01 & 0 & 0 & 0 & 0 \\
14 & Ret. Perizinan tertentu & 0 & 0 & 0 & 0 & 0 & 0 \\
15 & Ret. Pelayanan Pasar & 0 & 0 & 0 & 0 & 0 & 0 \\
16 & Ret. Tempat rekreasi dan olaraga & 0 & 0 & 0 & 0 & 0 & 0 \\
17 & Ret. Cetak Peta & 0 & 0 & 0 & 0 & 0 & 0 \\
18 & Lain-lain pend.daerah yang dipisahkan & 0,09 & 0,25 & 0 & 0 & 0 & 0,06 \\
19 & Sumbangan Pihak ketiga & 0,01 & 0 & 0 & 0 & 0 & 0 \\
20 & Jasa umum ketenagakerjaan & 0 & 0 & 0 & 0 & 0 & 0 \\
21 & Ret. Izin tempat penjualan minuman & 0,01 & 0 & 0 & 0 & 0 & 0 \\
22 & PKB Mobil Penumpang Sedan & 0 & 0 & 0 & 0 & 0 & 0 \\
23 & PKB Mobil Penumpang Minibus & 0 & 0 & 0 & 0 & 0 & 0 \\
& & & & & Jumlah Rata-Rata & 0,78 \\
\hline
\end{tabular}

Identifikasi Jenis Pajak dan Retribusi Daerah. Berdasarkan perhitungan terhadap setiap jenis pajak dan retribusi daerah dapat diidentifikasi melalui klasifikasi terlihat pada Tabel 7 dan Tabel 8 berikut ini: 
Tabel 7. Klasifikasi jenis pajak daerah

Kabupaten Halmahera Utara, Tahun 2012-2016

\begin{tabular}{lllcccc}
\hline No & \multicolumn{1}{c}{ Jenis } & \multicolumn{5}{c}{ Klasifikasi } \\
\cline { 2 - 7 } & \multicolumn{1}{c}{ Pajak Daerah } & $\mathbf{2 0 1 2}$ & $\mathbf{2 0 1 3}$ & $\mathbf{2 0 1 4}$ & $\mathbf{2 0 1 5}$ & $\mathbf{2 0 1 6}$ \\
\hline 1 & Pajak Hotel & - & Terbelakang & Terbelakang & Terbelakang & Terbelakang \\
2 & Pajak Restoran & - & Berkembang & Terbelakang & Terbelakang & Terbelakang \\
3 & Pajak Hiburan & - & Terbelakang & Berkembang & Terbelakang & Terbelakang \\
4 & Pajak Reklame & - & Terbelakang & Terbelakang & Terbelakang & Terbelakang \\
5 & Pajak Penerangan jalan & - & Terbelakang & Terbelakang & Terbelakang & Terbelakang \\
6 & Pajak Mineral bukan Logam & - & Terbelakang & Terbelakang & Terbelakang & Terbelakang \\
7 & BPHTB & - & Terbelakang & Terbelakang & Berkembang & Terbelakang \\
8 & Pajak Bumi dan Bangunan & - & - & Terbelakang & Terbelakang & Terbelakang \\
9 & Pajak Air Bawah Tanah & - & - & - & - & - \\
\hline
\end{tabular}

Perhitungan Potensi riil Pajak Restoran dan Ijin Mendirikan Bangunan (IMB). Berdasarkan Tabel 3 dapat dilihat bahwa pertumbuhan pajak restoran cukup tinggi dibandingkan pajak lainnya yaitu sebesar 2,29\%, meskipun dari perhitungan analisis overlay diketahui bahwa pajak restoran belum terklasifikasi sebagai pajak yang potensial tetapi dengan tingkat pertumbuhan yang tinggi pajak restoran dapat dikembangkan. Berdasarkan Tabel 4 terlihat bahwa retribusi IMB (Ijin Mendirikan Bangunan) mengalami pertumbuhan yang lebih tinggi dibandingkan retribusi lainnnya yaitu sebesar 2,25\%. Dalam hal ini retribusi IMB masih belum terklasifikasi sebagai pajak yang potensial yang diketahui dari perhitungan analisis overlay. Namun, dengan adanya tingkat pertumbuhan yang tinggi dari retribusi IMB maka retribusi ini berpotensi untuk dikembangkan.

Tabel 8. Klasifikasi jenis retribusi daerah

Kabupaten Halmahera Utara tahun 2012-2016

\begin{tabular}{|c|c|c|c|c|c|c|}
\hline \multirow{2}{*}{ No } & \multirow{2}{*}{$\begin{array}{l}\text { Retribusi } \\
\text { Daerah }\end{array}$} & \multicolumn{5}{|c|}{ Klasifikasi } \\
\hline & & 2012 & 2013 & 2014 & 2015 & 2016 \\
\hline 1 & Ret. Pelayanan Persampahan & - & Terbelakang & Terbelakang & Terbelakang & Terbelakang \\
\hline 2 & Ret. IMB & - & Terbelakang & Terbelakang & Berkembang & Terbelakang \\
\hline 3 & Ret. Pelayanan Kesehatan & - & Terbelakang & Berkembang & Terbelakang & Terbelakang \\
\hline 4 & Ret. Cetak KTP dan AKTE & - & Terbelakang & Terbelakang & Terbelakang & Terbelakang \\
\hline 5 & Ret. Pengujian Kendaraan Bermotor & - & Terbelakang & Terbelakang & Terbelakang & - \\
\hline 6 & Ret. Terminal & - & Terbelakang & Terbelakang & - & - \\
\hline 7 & Ret. Izin Trayek & - & Terbelakang & Terbelakang & Terbelakang & Terbelakang \\
\hline 8 & Ret. Parkir & - & Terbelakang & Terbelakang & Terbelakang & Terbelakang \\
\hline 9 & Ret. Jasa Pelabuhan Laut & - & Terbelakang & Terbelakang & Terbelakang & Terbelakang \\
\hline 10 & Ret. Jasa Pelabuhan Udara & - & Terbelakang & Terbelakang & Terbelakang & Terbelakang \\
\hline 11 & Ret. Menara Telkom & - & - & - & Terbelakang & - \\
\hline 12 & Ret. Rumah Potong Hewan & - & Terbelakang & Terbelakang & Terbelakang & Terbelakang \\
\hline 13 & Ret. Izin gangguan & - & Terbelakang & Terbelakang & Terbelakang & Terbelakang \\
\hline 14 & Ret. Perizinan tertentu & - & Terbelakang & Terbelakang & Terbelakang & Terbelakang \\
\hline 15 & Ret. Pelayanan Pasar & - & Terbelakang & Terbelakang & Terbelakang & Berkembang \\
\hline 16 & Ret. Tempat rekreasi dan olaraga & - & Terbelakang & Berkembang & Terbelakang & Terbelakang \\
\hline 17 & Ret. Cetak Peta & - & - & - & - & - \\
\hline 18 & $\begin{array}{l}\text { Lain-lain pendaapatan daerah yang } \\
\text { dipisahkan }\end{array}$ & - & Berkembang & Terbelakang & Terbelakang & - \\
\hline 19 & Sumbangan Pihak ketiga & - & Terbelakang & Terbelakang & Terbelakang & Terbelakang \\
\hline 20 & Jasa umum ketenagakerjaan & - & Terbelakang & Berkembang & - & - \\
\hline 21 & Ret. Izin tempat penjualan minuman & - & Terbelakang & Terbelakang & Terbelakang & Terbelakang \\
\hline 22 & PKB Mobil Penumpang Sedan & - & - & - & - & - \\
\hline 23 & PKB Mobil Penumpang Minibus & - & - & - & - & - \\
\hline
\end{tabular}




\section{KESIMPULAN DAN SARAN}

\subsection{Kesimpulan}

Berdasarkan hasil pembahasan dapat ditarik kesimpulan bahwa:

1. Pertumbuhan terbesar pajak daerah di Kabupaten Halmahera Utara selama 5 (lima) tahun periode pengamatan adalah pajak restoran dengan 2,29\% per tahun.

2. Pertumbuhan terbesar retribusi daerah di Kabupaten Halmahera Utara selama 5 (lima) tahun periode pengamatan adalah retribusi IMB (Ijin Mendirikan Bangunan) sebesar 2,25\% per tahun.

3. Pajak restoran adalah pajak yang memiliki potensi untuk dikembangkan. Sedangkan retribusi IMB adalah retribusi yang cukup memiliki potensi untuk lebih dikembangkan.

\subsection{Saran}

Adapun saran dari peneliti adalah :

1. Untuk pajak dan retribusi yang sudah berkategorikan berkembang bisa lebih ditingkatkan lagi agar dapat menjadi pajak dan retribusi daerah yang potensial. Perhatian pemerintah daerah ditujukan kepada pajak daerah dan retribusi daerah yang berkategorikan berkembang agar jenis pajak dan retribusi dapat memberikan kontribusi yang besar bagi total pajak dan retribusi daerah.

2. Pemerintah daerah diharapkan mengembangkan potensi jenis pajak dan retribusi daerah yang ada di Kabupaten Halmahera Utara sehingga jenis pajak dan retribusi daerah tersebut dapat meningkat setiap tahunnya dan memberikan konrtibusi yang besar terhadap pajak dan retribusi daerah serta menjadi sektor unggulan dalam pemasukan pajak dan retribusi daerah.

3. Kontrol pemerintah untuk instansi terkait agar lebih ditingkatkan lagi supaya tercipta kinerja yang baik untuk tahun-tahun selanjutnya dapat memberikan hasil memuaskan dari pemungutan pajak daerah dan retribusi daerah.

\section{DAFTAR PUSTAKA}

Frediyanto, Yanuar. 2010. Analisis keuangan kabupaten diprovinsi Jawa Tengah sebelum dan sesudah kebijakan otonomi Daerah. Skripsi Program S1 Fakultas Ekonomi Universitas Diponegoro. Semarang

Halim, Abdul. 2004. Akuntansi Keuangan Daerah. Jakarta. Salemba Empat

Husnia, Fitria Nur. 2016. Analisis Penerapan elektronik Pajak Bumi dan Bangunan ( E-PBB) (study pada Dinas Pendapatan Daerah Kabupaten Lamongan ). Jurnal Perpajakn (JEJAK)

Mardismo. 2016. Perpajakan. Edisi Terbaru. Penerbit Andi . Yogyakarta.

Mardismo, 2011. Perpajakan revisi. Penerbit Andi. Yogyakarta.

Pemerintah RI, Undang-Undang RI No.28 Tahun 2009 tentang Pajak Daerah dan Retribusi Daerah.

Pohan, Chairil Anwar. 2013. Manajemen Perpajakan. Gramedia Pustaka Utama. Jakarta.

Pontoh, Winston. 2013. Akuntansi Konsep dan Aplikasi Halaman Moeka. Jakarta Barat

Rizaldy, $\quad$ Fachmi. 2015. Analisis Potensi Pendapatan. http://www.academia.edu/577475/ANALISIS_POTENSI_PENDAPATAN. Diakses November 26, 2015.

Sari, Diana. Konsep Dasar Perpajakan. Bandung:Refika Aditama.

Sutarman, 2012. Pengantar Teknologi Informasi. Bumi Aksara. Jakarta.

Waney, Theo Rudolf. 2015. Evaluasi Pajak Hiburan Terhadap Pendapatan Asli Daerah Kota Manado.Universitas Sam Ratulangi. 